\title{
Emerging green routes to nanocellulose
}

\author{
Rosaria Ciriminna $^{1}$, Mina Gharhemani ${ }^{1}$, Babak Karimi ${ }^{1}$, and Mario Pagliaro ${ }^{1}$ \\ ${ }^{1}$ Affiliation not available
}

May 9, 2022

\begin{abstract}
Nanocellulose is an exceptional biomaterial whose industrial applications in widely different sectors and technologies so far were chiefly limited by the high cost of its multi-step extraction routes. Extraction methods of cellulose nanocrystals or nanofibers, indeed, generally involve energy-intensive mechanical treatment of wood pulp, treatment with concentrated H2SO4 to obtain cellulose nanocrystals, or chemical oxidation of the nanofibers followed by mechanical fibrillation of the partly oxidized fibers. In the last decade (2011-2021) a number of new green routes to cellulose nanofibers and nanocrystals have been developed. This study provides a critical outlook of such emerging green new routes to this versatile and safe bionanomaterial that once sustainably produced, preferably from low cost cellulosic biowaste, will become uniquitous in a number of different industrial products.
\end{abstract}

\section{Introduction}

First isolated in 1977 in the form of a translucent hydrogel at a USA-based paper and pulp company by repeated treatment of a $3 \%$ slurry of chopped wood pulp fibers with a high-pressure milk homogenizer, the new biomaterial later called nanocellulose was termed "microfibrillated cellulose" (MFC). ${ }^{1}$ "At the high temperature the high forces (pressure/cavitation/shear/impact) of the homogenizer acting in tandem or sequentially" wrote Turbak in 2015 "had broken down the cell walls of the microfibers and liberated the desired nanofibrils". ${ }^{2}$

Nanocellulose, namely cellulose fibrils with widths in the nanometer range, ${ }^{3}$ was born. Explicitly mentioning its "uses and commercial potential" in early research reports, ${ }^{1}$ chemists understood that the material had numerous potential applications.

In the subsequent four decades, scientists from across the world discovered the exceptional mechanical, optical, chemical, biological and thermal properties of the new bionanomaterial. ${ }^{3,4}$ Coupled to full recyclability, biodegradability, and lack of toxicity, said properties make nanocellulose and nanocellulose-based composites suitable for application in a vast array of industrial fields. Composites, furthermore, are easily obtained through the straightforward combination of highly hydrophilic nanocellulose with inorganic and organic substances. ${ }^{5}$

Numerous excellent books ${ }^{6,7,8}$ describe the structure and the preparation routes of different nanocelluloses, with recent monographs devoted to specific applications of nanocellulose for instance in electronics ${ }^{9}$ or in water treatment..$^{10}$

From nanocellulose-based aerogels, 11 through energy storage systems, 12 applications in biomedicine, 13 environmental remediation, ${ }^{14}$ and catalysis, ${ }^{15}$ numerous review articles on nanocellulose uses have been published. Hence, rather than adding a new review in a rapidly evolving research field, this study provides a critical outlook on the emerging green production routes of this "ageless bionanomaterial". ${ }^{16}$ 
To put the discussion in context, we first briefly discuss the current production routes, some of which have been commercialized, from an economic viewpoint. We then present the main emerging green chemistry production methods. The study concludes suggesting new avenues to tackle environmental issues using nanocelluloses sourced from cellulosic biowaste ${ }^{17}$ based on these new environmentally friendly production routes.

\section{Current production routes}

Nanocellulose is generally sourced from wood pulp as cellulose nanofiber (CNF) or cellulose nanocrystal (CNC). In addition, highly pure (and expensive) bacterial nanocellulose (BNC) is industrially synthesized on small scale from glucose using Gluconoacetobacter xylinus bacteria. "The way to produce bacterial nanocellulose today", however, "is expensive and the methods are inefficient". ${ }^{18}$

A recent review describes the main nanocellulose production routes. ${ }^{19}$ In general, harsh chemical conditions and large amounts of energy and harmful chemical compounds are required, with the undesired production of large effluent amounts. This has intrinsically limited the large-scale production of nanocellulose.

Nanocellulose fibrils are extracted from wood pulp obtained via pulping and bleaching either via acid hydrolysis with sulfuric acid (further adding wastewater to the process), enzymatically (requiring long extraction times and with relatively low efficiency), or mechanically via high-pressure homogenization. ${ }^{20}$ Steam explosion or ultrasonication, with high-energy consumption, are also suitable. ${ }^{21}$

Hydrolysis with aqueous $\mathrm{H}_{2} \mathrm{SO}_{4}$ affords nanocellulose in nanocrystal form. Comprised of cellulose I only, CNC has a low length/diameter "aspect" ratio (10-100), and a tensile strength similar to that of aramid-fiber (10 $\mathrm{GPa}$ ). Its industrial production has an estimated production cost ranging from $\$ 3632 / \mathrm{t}$ to $\$ 4420 / \mathrm{t} .{ }^{22}$ Feedstock cost and capital investment being the major cost drivers. ${ }^{22}$ Remarkably, in the same year of these estimates (2017) for large scale production, CNC was reported to be actually sold at $\$ 1,000 / \mathrm{kg} .{ }^{23}$

Chiefly manufactured using TEMPO-mediated oxidation of wood cellulose followed by mechanical dispersion of the oxidized fibers, CNF has a higher length/diameter ratio (100-150). Its structure includes both amorphous cellulose and crystalline cellulose I. The 2,2,6,6-tetramethylpiperidine-1-oxyl radical (TEMPO) used for the selective oxidation of primary alcohol groups in polysaccharides (aqueous $\mathrm{NaOCl}$ as primary oxidant in the presence of a catalytic amount of bromide at $\mathrm{pH} 9-10)^{24}$ partly oxidises the primary alcohol groups of water-insoluble cellulose to carboxylate groups. ${ }^{25}$

It is enough to mechanically grind or sonicate the TEMPO-oxidized cellulose to liberate the oxidized cellulose fibers into a homogeneous, highly viscous suspension of $3-5 \mathrm{~nm}$ cellulose nanofibrils. ${ }^{25}$ The electrostatic repulsions between the cellulose fibrils bearing the $\mathrm{COO}^{-}$groups ensures good dispersion and high stability of the nanofibrils in solution. Repulsion among the carboxylated fibers, furthermore, causes a decrease in the electricity consumed to power the mechanical fibrillation process.

Since 2017, the process is used by a large paper company in Japan to manufacture CNF in the form of dispersed nanofibers with uniform fiber width of 3 to $4 \mathrm{~nm} .{ }^{26}$ The company starts from bleached wood pulp at two different paper mills, and supplies the "Cellenpia" product series to different industrial customers producing CNF-reinforced tires, paper barrier cups for beverages, personal care, hygiene, and cosmetic products. ${ }^{26}$ In 2019 , the same company successfully developed a CNF-reinforced composite subsequently used to produce a car whose weight was about $10 \%$ lower than a conventional car made in steel. ${ }^{27}$

Currently CNF is sold at a cost of $\$ 90-100 / \mathrm{kg} .{ }^{28}$ This high cost is due to the high cost of TEMPO and to the cost of processing the spent hypochlorite dilute solution containing the genotoxic TEMPO catalyst (as well as corrosive $\mathrm{NaBr}$ ). ${ }^{29}$ Separating nitroxyl radicals in solution is a multi-step, expensive process, ${ }^{30}$ whereas TEMPO concentration in any material suitable for biomedical use, must be lower than the threshold of toxicological concern (i.e., $4 \mathrm{ppm}){ }^{31}$

\section{Emerging green routes}


Reviewing research published between 2015 and 2020 concerning new CNF/CNC preparation routes, Li and co-workers identified 69 studies. ${ }^{19}$ All new processes included two or three pretreatment steps, followed by chemical and mechanical treatment. Amid the mechanical treatment processes, ultrasonication was found to be dominant.

Another recent comprehensive review on new extraction methods from cellulosic biowaste, reported that sugarcane bagasse with its high lignocellulose content and loose structure, and algae residues are the biowastes most suited to extract nanocellulose. ${ }^{32}$

Poor in lignin and available in huge yearly amount, citrus processing waste (CPW) obtained from the citrus juice industry is another ideal cellulose feedstock. The annual production of citrus fruits exceeds 120 million tons. More than half of the fruit is non-edible and discarded as waste. Alone, the global volume of citrus fruits yearly squeezed at citrus juice plants exceeds 31 million tonnes, $50-60 \%$ of which is waste. ${ }^{33}$

Unfortunately, the routes to citrus nanocellulose starting from CPW based on enzymatic, ${ }^{34}$ microwaveassisted hydrothermal treatment, ${ }^{35}$ and acid hydrolysis, ${ }^{36}$ all present significant technical limitations. For example, the nanocellulose fibrils obtained via multi-step microwave-assisted extraction of dried depectinated orange peel are deeply colored in brown. ${ }^{35}$ This is due both to caramelized sugars and to the Maillard reaction between sugars and residual proteins at the high temperatures $\left(120^{\circ} \mathrm{C}\right.$ to $\left.180^{\circ} \mathrm{C}\right)$ required for extraction. ${ }^{35}$

One entirely green route to nanocellulose in CNC form was reported by Huang and co-workers in 2018. ${ }^{37}$ The team used ball milling of cellulose in water only, followed by centrifugation. The process quickly affords cellulose disintegration down to elementary fibrils 3-10 nm wide and 120-400 $\mathrm{nm}$ long.

To understand the relevance of this discovery, it is instructive to compare it to enzymatic hydrolysis with cellulase enzymes. Applied to eucalyptus cellulose pulp using a new commercial enzymatic complex at cellulose loading of $10 \%\left(\mathrm{w} / \mathrm{v}\right.$ ) and enzyme loading of $10 \mathrm{mg} / \mathrm{g},{ }^{38}$ or even relying on a cellulolytic enzymatic complex produced on-site by Aspergillus niger followed by sonication, ${ }^{39}$ the optimal enzymatic process affords a $24.6 \%$ yield in CNC (after $96 \mathrm{~h}$ of enzymatic hydrolysis of cellulose pulp, followed by 5 min sonication).

As mentioned above, the TEMPO-mediated carboxylation of cellulose and production of nanocellulose has already been commercialized. ${ }^{26}$ Numerous practically relevant discoveries using heterogenized TEMPO catalysts showed evidence, on laboratory scale, how shifting the CNF production process from using TEMPO in solution to new generation heterogeneous TEMPO catalysts has substantial benefits in terms of enhanced quality of the resulting $\mathrm{CNF}$ and reduced environmental impact. ${ }^{40}$

Interestingly, Turbak recognized that cavitation was among the "high forces of the homogenizer" 2 responsible for cellulose fibrillation using the high pressure homogenizer. More than 40 years after Turbak and co-workers discovery, ${ }^{1}$ in 2010 Pandit and Pinjari were the first to report the outcomes of acoustic cavitation (AC) and hydrodynamic cavitation (HC) applied to a $1 \% \mathrm{w} / \mathrm{v}(0.5 \mathrm{~kg}$ in $50 \mathrm{~L}$ water) aqueous suspension of $63 \mathrm{~mm}$ cellulose microparticles. ${ }^{41}$ 


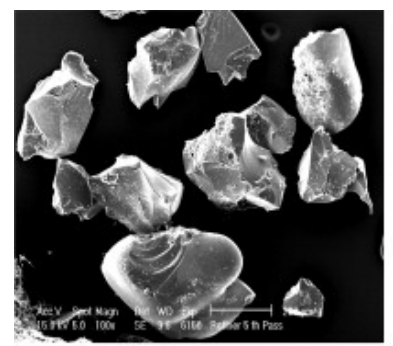

A

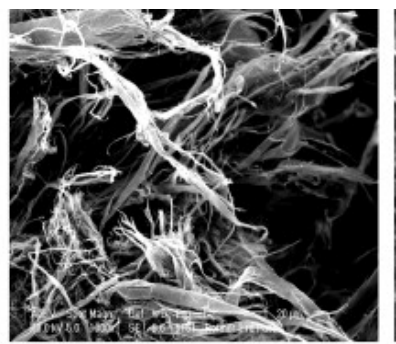

B

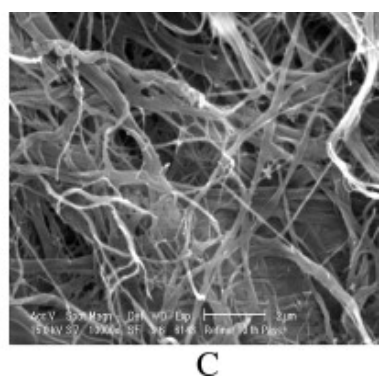

Figure 1: SEM images of $(A)$ initial sample at $100 \times$, (B) hydrodynamically processes sample at $5000 \times$, and (C) ultrasonically processes sample at 10,000×. [Reproduced from Ref.41, Creative Commons Attribution (CC BY) license].

The team called "declumping" the fibrillation of the bulk cellulose diven by by both AC and HC (Figure 1). Indeed, ultrasonically processed cellulose was completely fibrillated into individually separated fibrils less than $100 \mathrm{~nm}$ thick due to the more intense cavitational collapse and absence of fluid flow of acoustic cavitation, whereas hydrodynamic cavitation resulted into full cellulose fiber-fiber detachment, with some fibers at nano level and most of the fibers of micrometer thickness.

Both forms of cavitation reduced cellulose crystallinity from $87 \%$ to $38 \%$. Such dominant presence of amorphous domains enhances the flexibility and plasticity of the material, and lowers both stiffness and elasticity. ${ }^{42}$ The particle size decreased from $63 \mu \mathrm{m}$ to 1.36 and $0.3 \mathrm{~mm}$ for the hydrodynamically and ultrasonically processed cellulose samples, respectively. Due to decrystallization, the thermal stability of the newly obtained nanocelluloses was significantly higher.

We briefly remind that the cavitation bubbles generated in water via acoustic or hydrodynamic cavitation upon collapse locally release short-lived (ms duration) shockwaves of extreme pressures (1000-2000 atm) and temperatures $(5000 \mathrm{~K})$ that are ideally suited for the extraction of natural products. ${ }^{43}$

Two years later, Paquin and co-workers in Quebec reported that by carrying out the TEMPO-mediated oxidation of a diluted suspension ( $1 \mathrm{wt} \%$ ) of bleached hardwood kraft pulp in a $45 \mathrm{~L}$ flow-through sonoreactor, a $87.5 \%$ decrease in energy consumption (in comparison to the process in batch reactor) and a $95 \%$ higher production rate of oxidized fibers (compared to reaction without any ultrasound in batch mode) could be achieved. ${ }^{44}$ These results, the team concluded, suggest the possibility of scaling up the process on industrial scale directly in continuous mode.

The original discovery of Pandit and Pinjari using no added chemicals to fibrillate crystalline cellulose, however, remained without further investigation until the teams of Meneguzzo and Pagliaro demonstrated the process on semi-industrial scale by processing via $\mathrm{HC}$ more than $30 \mathrm{~kg}$ of citrus (lemon and grapefruit) processing waste in $120 \mathrm{~L}$ water. ${ }^{45}$

team called "declumping" the fibrillation of the bulk cellulose diven by by both AC and HC (Figure 1). Indeed, ultrasonically processed cellulose was completely fibrillated into individually separated fibrils less than $100 \mathrm{~nm}$ thick due to the more intense cavitational collapse and absence of fluid flow of acoustic cavitation, whereas hydrodynamic cavitation resulted into full cellulose fiber-fiber detachment with some fibers at nano level and most of the fibers of micrometer thickness.

Both forms of cavitation reduced cellulose crystallinity from $87 \%$ to $38 \%$. Such dominant presence of amorphous domains enhances the flexibility and plasticity of the material, and lowers both stiffness and elasticity. ${ }^{42}$ The particle size decreased to $1.36 \mu \mathrm{m}$ and $0.3 \mu \mathrm{m}$ for the hydrodynamically and ultrasonically processed cellulose samples, respectively. whose thermal stability was significantly higher of the newly obtained nanocelluloses due to decrystallization. 
We briefly remind that the cavitation bubbles generated in water via acoustic or hydrodynamic cavitation upon collapse locally release short-lived ( $\mu$ s duration) shockwaves of extreme pressures (1000-2000 atm) and temperatures $(5000 \mathrm{~K})$ that are ideally suited for the extraction of natural products. ${ }^{43}$

Two years later, Paquin and co-workers in Quebec reported that by carrying out the aminoxyl-radical mediation oxidation of a diluted suspension (1 wt\%) of bleached hardwood kraft pulp in a $45 \mathrm{~L}$ flow-through sonoreactor, a $87.5 \%$ decrease in energy consumption (in comparison to the process in batch reactor) and a $95 \%$ higher production rate of oxidized fibers (compared to reaction without any ultrasound in batch mode) are achieved. These results, the team concluded, suggest the possibility of scaling up the process on industrial scale directly in continuous mode. ${ }^{44}$

The original discovery of Pandit and Pinjari using no added chemicals to fibrillate crystalline cellulose, however, remained without further investigation until the teams of Meneguzzo and Pagliaro demonstrated the process on semi-industrial scale by processing via $\mathrm{HC}$ more than $30 \mathrm{~kg}$ of citrus (lemon and grapefruit) processing waste in $120 \mathrm{~L}$ water. ${ }^{45}$

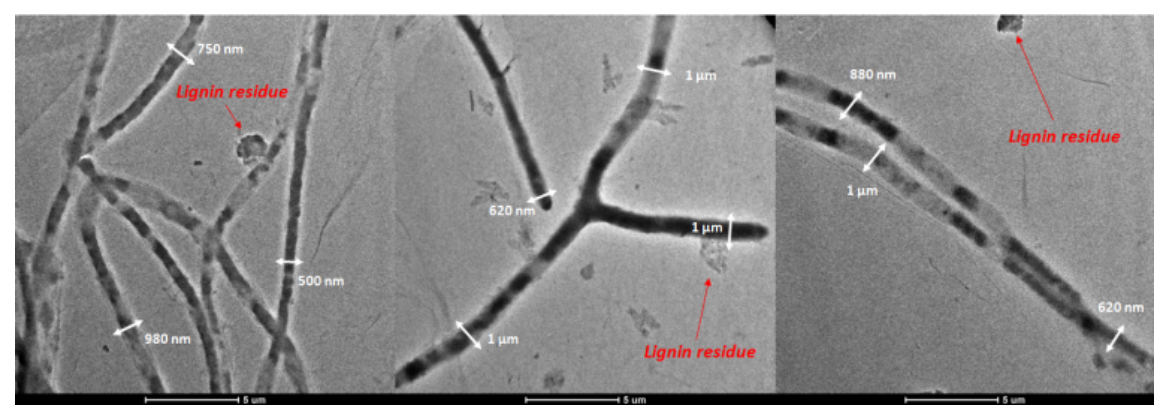

Figure 2: TEM images of grapefruit CytroCell focusing on selected single fibrils. [Reproduced from Ref.45, Creative Commons Attribution (CC BY) license].

The team dubbed "CytroCell" the new micronized cellulose. Both new CytroCell materials consist of cellulose of low crystallinity index ( 0.33 for lemon and 0.36 for grapefruit). Lemon "CytroCell" consists of 0.5-3 micron long microfibrils whose section varies between about 110 and $420 \mathrm{~nm}$. Grapefruit CytroCell is comprised of ramified microfibrils whose diameter varies from $500 \mathrm{~nm}$ to $1 \mu \mathrm{m}$ (Figure 2). ${ }^{46}$

The one-pot process requires no subsequent mechanical treatment of the fibrillated nanofibers. In brief, the highly efficient $\mathrm{HC}$ creates cavitation bubbles which fibrillate and promote decrystallization of the citrus peel microcrystalline cellulose fibers. The effect is intensified by the presence of the residual citric acid relatively abundant in the wet CPW used as cellulose source, such as in the case of acoustic cavitation applied to microcystalline cellulose in the presence of $0.2 \mathrm{M}$ citric acid. ${ }^{47}$

\section{Outlook and perspectives}

Comparing four routes to wood pulp-derived nanocellulose (TEMPO-oxidation followed by sonication or homogenization and chloroacetic etherification followed by sonication or homogenization), Renneckar and co-workers recently found that TEMPO oxidation followed by homogenization is the lowest impact nanocellulose process. ${ }^{48}$ For comparison, the energy and environmental impact factors for nanocellulose industrial production using the latter optimal route are, respectively, 4 and 20 times larger than the kraft pulp production.

Whether using concentrated $\mathrm{H}_{2} \mathrm{SO}_{4}$ to hydrolyze the amorphous regions of cellulose and isolate $\mathrm{CNC},{ }^{22}$ or relying on the TEMPO-catalyzed process with bleach as primary oxidant and bromide as co-catalyst followed by mechanical treatment to afford $\mathrm{CNF},{ }^{25,26}$ current nanocellulose production methods are capital-intensive 
and have high operating costs. In the case of CNC, feedstock cost and capital investment are the major cost drivers, with sulfuric acid and lime consumption alone accounting for $25 \%$ of production costs for the lowest plant configuration (without acid recovery). ${ }^{22}$

In the case of CNF, high manufacturing costs are due to the large amount of electrical energy required for homogenization, followed by the high cost of the TEMPO catalyst. ${ }^{49}$ Furthermore, a large amount of solvent is needed to separate the CNF from genotoxic TEMPO, while the expensive TEMPO catalyst is lost in the reaction effluents. The method to recover the TEMPO catalyst in a mixture of a water-miscible organic solvent and water,30 could not be industrialized in the cellulose oxidation process carried out in water only likely due to high cost. ${ }^{50}$

It is perhaps not surprising to find that the first large nanocellulose production plants are operated by paper and pulp companies. ${ }^{26}$ Paper companies indeed are facing a dramatic fall in paper demand following the advent of the internet and other digital technologies. ${ }^{51}$ Beyond the aforementioned paper and pulp company producing CNF at two production sites in Japan, ${ }^{26}$ another paper and pulp company based in Norway since late 2016 produces MFC at a production site with a 1,000 t/a capacity. The ingredient is shipped to different industrial customers as $2 \%$ or $10 \%$ aqueous formulation. ${ }^{52}$

Comparing CNC chiefly extracted from different producers via hydrolysis with concentrated $\mathrm{H}_{2} \mathrm{SO}_{4}$ and purified according to different procedures, Cranston and Reid lately found that all products share the same basic chemical structure and physicochemical properties of laboratory-made CNC. ${ }^{53}$

Still, both main nanocellulose production methods need to be made less energy and capital intensive. Beyond enzymatic extraction, 39 three methods are ready for optimization, scale up and commercialization: the heterogeneously catalyzed oxidation over new generation solid TEMPO catalysts, 40 (including magnetically recoverable Karimi's nanocatalyst) ${ }^{54}$ ball-milling in the presence of water of cellulose ${ }^{37}$ and (for applications of nanocellulose of low crystallinity) acoustic and hydrodynamic cavitation. ${ }^{41,44,45}$ All are promising considering that many of the aforementioned catalysts are now commercial (Karimi's nanocatalyst in the form of $50 \mathrm{~nm}$ beads easily recovered with a magnet) $;^{55}$ whereas the safe and robust HC process for the extraction of natural products such as waste orange peel is easily scaled-up. ${ }^{56}$

Enzymatic extraction, too, is an eminently clean nanocellulose production process. ${ }^{38,39}$ Dr Farinas in Brazil is one of the leading scholars in the field. Asked whether companies are using enzymatic extraction, she noted that:

"The use of enzymes to obtain nanocellulose is very challenging, but I believe it is a very promising alternative route. I believe that there are few companies using enzymes to obtain nanocellulose, but mostly to facilitate the production of nanofibrillated cellulose, as far as I know. One of them is VTT, using the HefCel concept in which enzymes facilitate the mechanical process". 57

"HefCel" stands for "high-consistency enzymatic fibrillation technology", a process developed at VTT Technical Research Centre of Finland, in which cellulose fibrils are produced at high consistency (20-40\%) by stirring concentrated cellulose pulp (20-40\%) in the presence of a tailored cellulase enzyme mixture. ${ }^{58}$ The process results in $90 \%$ yield in fibrillated cellulose, while the low water content lowers the cost of drying.

Though not providing a timeline, market projections dating back to 2014 estimated a potential volume of nanocellulose exceeding 6.4 million tonnes/year only in the USA (5.9 million tons/year only in the high volume category, and 0.48 tonnes/year in the low volume category). ${ }^{59}$ Four years later, however, the nanocellulose market did not reach 40,000 tonnes (39,600 tonnes), with the large majority of being produced at pulp mills in form of MFC used in their own paper and paperboard products. ${ }^{60}$

In 2020, the nanocellulose market value amounted to about $\$ 300$ million globally, with dried bacterial nanocellulose selling at $\$ 50 / \mathrm{g}, 61$ and the world's largest nanocellulose production plant having a capacity of 2.5 t/day. ${ }^{60}$

It is instructive to learn that, besides use of MFC on paper and paperboard products, the main uses of 
nanocellulose currently concern low volume, and high value applications of CNF. For example, in Japan, the world's leading CNF manufacturing country, products using CNF include biodegradable cutlery of enhanced strength; foam materials for the midsole of sport shoes; CNF-coated diaphragm for speakers and television sets; coating agent to prevent concrete adhesion; and undercoat paint preventing discoloration of the base material and cracks in the paint film. ${ }^{62}$

For nanocellulose-enabled technologies 5-10 to find practical utilization and large industrial uptake there is a need for green production technologies through which scale up production, lower production costs and make nanocellulose available to industrial customers at affordable price. This, inter alia, requires to switch from expensive wood pulp (priced at $\$ 907 /$ tonne as of April 2021) ${ }^{63}$ to low cost and abundant biowaste as cellulose source.

Poor in lignin, and available in over 31 million tonnes/year, citrus biowaste whose other main component, pectin, is in high and increasing demand since more than a decade, ${ }^{64}$ is an ideal nanocellulose source in a integrated biorefinery. ${ }^{65}$

As put it by Jessop and Reyes, in scientific publications that use the "green chemistry" terminology, "there is an inversely proportional relationship between the number of papers published in an area and its associated environmental impact". ${ }^{66}$ This is true also for nanocellulose production where the raw material originates from agrifood and forestal (paper and pulp, citrus, sugarcane, etc.) companies which are slowly, but inevitably, transforming into bioeconomy firms. ${ }^{26,52}$

Though originating from apparently distant areas such as heterogeneous catalysis, enzymatic catalysis and acoustic or hydrodynamic cavitation, the new green chemistry technologies to manufacture nanocellulose are ready to be scaled up and, if found technically and economically viable, uptaken by industry. To accelerate this progress, the new bioeconomy industry needs young researchers trained in the aforementioned chemical and physicochemical technologies, and with a critical knowledge of the field. ${ }^{67}$

This study offers such critical outlook en route to mass uptake of this versatile, robust and safe bionanomaterial sustainably produced and preferably sourced from low cost cellulosic biowaste.

\section{Acknowledgements}

We thank Dr. Cristiane Sanchez Farinas, Empresa Brasileira de Pesquisa Agropecuária (Embrapa), Brazil, for helpful correspondence. This study is dedicated to the memory of Professor Franco Piozzi (1928-2022), for nearly 40 years eminent Professor of organic chemistry at the University of Palermo.

\section{Conflict of interest}

The Authors declare no conflict of interest.

\section{References}

1. A.F. Turbak, F.W. Snyder, K.R. Sandberg, Microfibrillated cellulose, a new cellulose product: properties, uses, and commercial potential, In A. Sarko (Ed.) Proceedings of the Ninth Cellulose Conference, Applied Polymer Symposia, 37, Wiley, New York: 1983; pp. 815-827.

2. A.F. Turbak, Birth of nanocellulose, Tappi Over the Wire, 2015. www.naylornetwork.com/PPIOTW/articles $/$ ?aid=150993\&issueID=22333 (accessed January 5, 2022).

3. D. Klemm, F. Kramer, S. Moritz, T. Lindström, M. Ankerfors, D. Gray, A. Dorris, Nanocelluloses: A new family of nature-based materials, Angew. Chem. Int. Ed. 2011, 50, 5438-5466. https://doi.org/10. 1002/anie. 201001273 
4. A. Dufresne, Nanocellulose: a new ageless bionanomaterial, Mater. Today 2012, 16, 220-227. https: //doi.org/10.1016/j.mattod.2013.06.004

5. Handbook of Nanocellulose and Cellulose Nanocomposites, volumes 1 and 2, H. Kargarzadeh, I. Ahmad, S. Thomas, A. Dufresne (Ed.s), Wiley-VCH, Weinheim: 2017.

6. A. Dufresne, Nanocellulose, De Gruyter, Berlin: 2013.

7. J. Huang, A. Dufresne, N. Lin (Ed.s), Nanocellulose, Wiley-VCH, Weinheim: 2019.

8. K.-Y. Lee (Ed.), Nanocellulose and Sustainability, CRC Press, Boca Raton, FL: 2020.

9. Nanocellulose Based Composites for Electronics, S. Thomas, Y. Beeran Pottathara (Ed.s), Elsevier, Cambridge, MA: 2020.

10. Nanocellulose and its Composites for Water Treatment Applications, D. Kumar (Ed.), Routledge, London: 2021.

11. S. Ahankari, P. Paliwal, A. Subhedar, H. Kargarzadeh, Recent developments in nanocellulose-based aerogels in thermal applications: a review, ACS Nano 2021, 15, 3849-3874. https://doi.org/10.1021/ acsnano.0c09678

12. J.-H. Kim, D. Lee, Y.-H. Lee, W. Chen, S.-Y. Lee, Nanocellulose for energy storage systems: beyond the limits of synthetic materials, Adv. Mater. 2019,31, 1804826.https://doi.org/10.1002/adma.201804826

13. N. Lin, A. Dufresne, Nanocellulose in biomedicine: current status and future prospect, Eur. Polym. J. 2014, 59, 302-325.https://doi.org/10.1016/j .eurpolymj . 2014.07.025

14. K.P.Y. Shak, Y.L. Pang, S.K. Mah, Nanocellulose: Recent advances and its prospects in environmental remediation, Beilstein J. Nanotechnol. 2018, 9, 2479-2498.https://doi.org/10.3762/bjnano.9.232

15. M. Kaushik, A. Moores, Review: nanocelluloses as versatile supports for metal nanoparticles and their applications in catalysis, Green Chem. 2016, 18, 622-637.https://doi.org/10.1039/c5gc02500a

16. A. Dufresne, Nanocellulose: a new ageless bionanomaterial, Mater. Today 2013, 16, 220-227. https://doi.org/10.1016/j.mattod.2013.06.004

17. A. García, A. Gandini, J. Labidi, N. Belgacem, J. Bras, Industrial and crop wastes: A new source for nanocellulose biorefinery, Ind. Crops Prod. 2016, 93, 26-38. https://doi.org/10.1016/j.indcrop. 2016. 06.004

18. B. Alriksson, cit. in: S. Matthis, Bacterial nanocellulose can become a strength enhancer, pulpapernews.com, 2 May 2018. www.pulpapernews.com/20190803/9456/bacterial-nanocellulose-can-becomestrength-enhancer (accessed May 9, 2022).

19. C. Yadav, A. Saini, W. Zhang, X. You, I. Chauhan, P. Mohanty, X. Li, Plant-based nanocellulose: A review of routine and recent preparation methods with current progress in its applications as rheology modifier and 3D bioprinting, Int. J. Biol. Macromol. 2021, 166, 1586-1616. https://doi.org/10.1016/j. ijbiomac. 2020.11.038

20. P. Phanthong, P. Reubroycharoen, X. Hao, G. Xu, A. Abudula, G. Guan, Nanocellulose: extraction and application, Carbon Resour. Convers. 2018, 1, 32-43. https://doi.org/10.1016/j.crcon.2018.05.004

21. O. A. Titton Dias, S. Konar, A. Lopes Leão, W. Yang, J. Tjong, M. Sain, Current state of applications of nanocellulose in flexible energy and electronic devices, Front. Chem. 2020, 8, 420. https://doi.org/10. 3389/f chem. 2020.00420

22. C. Abbati de Assis, C. Houtman, R. Phillips, E.M. Bilek, O. J. Rojas, L. Pal, M. S. Peresin, H. Jameel, R. Gonzalez, Conversion economics of forest biomaterials: risk and financial analysis of CNC manufacturing, Biofuels, Bioprod. Bioref. 2017, 11, 682-700. https://doi.org/10.1002/bbb.1782 
23. B. Sithole, Roadmap towards innovation-driven forestry manufacturing, Biorefinery Industry Development Facility, Durban, South Africa, 4 October 2017. See at the URL: https://slideplayer.com/slide/ 13304284/ (accessed May 9, 2022).

24. A. E. de Nooy, A. C. Besemer, H. van Bekkum, Highly selective nitroxyl radical-mediated oxidation of primary alcohol groups in water-soluble glucans, Carbohydr. Res. 1995, 269, 89-98. https://doi.org/10. 1016/0008-6215(94)00343-e

25. T. Saito, Y. Nishiyama, J.-L. Putaux, M. Vignon, A. Isogai, Homogeneous suspensions of individualized microfibrils from TEMPO-catalyzed oxidation of native cellulose, Biomacromolecules 2006, 7, 16871691. https://doi.org/10.1021/bm060154s

26. Nippon Paper Group, Cellulose nanofiber manufacturing technology and application development, 2022. https://www.nipponpapergroup.com/english/research/organize/cnf.html (accessed May 9, 2022).

27. Research Institute for Sustainable Humanosphere, Nano cellulose vehicle project, 2019. http://www . rish.kyoto-u.ac.jp/ncv/ (accessed May 5, 2022).

28. M. Pagliaro, Cellulose nanofiber: An advanced biomaterial soon to become ubiquitous, Chim. Oggi 2018, 36 (4), 61-62.

29. G. Szekely, M. C. Amores de Sousa, M. Gil, F. Castelo Ferreira, W. Heggie, Genotoxic impurities in pharmaceutical manufacturing: sources, regulations, and mitigation, Chem. Rev. 2015, 115, 81828229. https://doi.org/10.1021/cr300095f

30. J. Jetten, A. Besemer, Process for the recovery of nitroxy compounds from organic solutions and oxidation process, US20050154206A1 (2005).

31. H. E. Strohmeyer, G. W. Sluggett, Determination and control of TEMPO, a potentially genotoxic free radical reagent used in the synthesis of filibuvir, J. Pharm. Biomed. 2012, 62, 216-219. https://doi.org/ $10.1016 / j \cdot j$ pba.2011.12.036

32. S. Yu, J. Sun, Y. Shi, Q. Wang, J. Wu, J. Liu, Nanocellulose from various biomass wastes: Its preparation and potential usages towards the high value-added products, Environ. Sci. Ecotechnol. 2021, 5, 100077. https://doi.org/10.1016/j.ese.2020.100077

33. M. Raimondo, F. Caracciolo, L. Cembalo, G. Chinnici, B. Pecorino, M. D'Amico, Making virtue out of necessity: Managing the Citrus waste supply chain for bioeconomy applications, Sustainability 2018, 10, 4821. https://doi.org/10.3390/su10124821

34. M. Mariño, L.L. Da Silva, N. Durán, L. Tasic, Enhanced materials from nature: nanocellulose from citrus waste, Molecules 2015, 20, 5908-5923. doi:10.3390/molecules20045908

35. E.M. De Melo, J.H. Clark, A.S. Matharu, The Hy-MASS concept: hydrothermal microwave assisted selective scissoring of cellulose for in situ production of (meso)porous nanocellulose fibrils and crystals. Green Chem. 2017, 19, 3408-3417. https://doi.org/10.1039/c7gc01378g

36. S. Naz, N. Ahmad, J. Akhtar, N.M. Ahmad, A. Ali, M. Zia, Management of citrus waste by switching in the production of nanocellulose. IET Nanobiotechnol. 2016, 10, 395-399. https://doi.org/10.1049/ietnbt. 2015.0116

37. X. Kang, S. Kuga, C. Wang, Y. Zhao, M. Wu, Y. Huang, Green preparation of cellulose nanocrystal and its application, ACS Sustainable Chem. Eng. 2018, 6, 2954-2960. https://doi.org/10.1021/acssuschemeng. $7 \mathrm{~b} 02363$

38. T.J. Bondancia, L.J. Corrêa, A.J. Cruz, L.H.C. Mattoso, J.M. Marconcini, A.C. Badino, C.S. Farinas, Production of cellulose nanofibers by enzymatic hydrolysis in a stirred tank reactor, XXI Simpósio Nacional de Bioprocessos e XII Simpósio de Hidrólise Enzimática de Biomassas, 3-6 September 2017, Aracaju, Brasil. 
39. P. Squinca, S. Bilatto, A.C. Badino, C.S. Farinas, Nanocellulose production in future biorefineries: an integrated approach using tailor-made enzymes, ACS Sustainable Chem. Eng. 2020, 8, 2277-2286. https: //doi.org/10.1021/acssuschemeng.9b06790

40. R. Ciriminna, A. Scurria, M. Pagliaro, Enhanced polysaccharide nanofibers via oxidation over Silia Cat TEMPO, Chem. Commun. 2021, https://doi.org/10.1039/d1cc02684d

41. D.V. Pinjari, A.B. Pandit, Cavitation milling of natural cellulose to nanofibrils, Ultrason. Sonochem. 2010, 17, 845-852. https://doi.org/10.1016/j.ultsonch.2010.03.005

42. C. Yadav, A. Saini, W. Zhang, X. You, I. Chauhan, P. Mohanty, X. Li, Plant-based nanocellulose: A review of routine and recent preparation methods with current progress in its applications as rheology modifier and 3D bioprinting, Int. J. Biol. Macromol. 2021, 166, 1586-1616. https://doi.org/10.1016/j. ijbiomac.2020.11.038

43. D. Panda, S. Manickam, Cavitation technology - the future of greener extraction method: a review on the extraction of natural products and process intensification mechanism and perspectives, Appl. Sci. 2019, 9, 766. https://doi.org/10.3390/app9040766

44. M. Paquin, É. Loranger, V. Hannaux, B. Chabot, C. Daneault, The Use of Weissler Method for scaleup a kraft pulp oxidation by TEMPO-mediated system from a batch mode to a continuous flow-through sonoreactor, Ultrason. Sonochem. 2013, 20,103-108, https://doi.org/10.1016/j . ultsonch. 2012.08.007

45. A. Scurria, L. Albanese, M. Pagliaro, F. Zabini, F. Giordano, F. Meneguzzo, R. Ciriminna, CytroCell: valued cellulose from citrus processing waste, Molecules 2021, 26, 596. https://doi.org/10.3390/ molecules 26030596

46. S. Al Jitan, A. Scurria, L. Albanese, M. Pagliaro, F. Meneguzzo, F. Zabini, R. Al Sakkaf, A. Yusuf, G. Palmisano, R. Ciriminna, Micronized cellulose from citrus processing waste using water and electricity only, Int. J. Biol. Macromol. 2022, 204, 587-592. https://doi.org/10.1016/j.ijbiomac.2022.02.042

47. E. Robles, N. Izaguirre, B.-I. Dogaru, C.-M. Popescu, I. Barandiaran, J. Labidi, Sonochemical production of nanoscaled crystalline cellulose using organic acids, Green Chem. 2020, 22, 4627-4639. https : //doi .org/ $10.1039 / \mathrm{d} 0 \mathrm{gc0} 1283 \mathrm{a}$

48. Q. Li, S. McGinnis, C. Sydnor, A. Wong, S. Renneckar, Nanocellulose life cycle assessment, ACS Sustainable Chem. Eng. 2013, 1, 919-928.https://doi.org/10.1021/sc4000225

49. A. Serra, I. González, H. Oliver-Ortega, Q. Tarrès, M. Delgado-Aguilar, P. Mutjé, Reducing the amount of catalyst in TEMPO-oxidized cellulose nanofibers: effect on properties and cost, Polymers 2017, 9, 557. https://doi.org/10.3390/polym9110557

50. M. Delgado-Aguilar, I. González, Q. Tarrés, M. Alcalá, M.A. Pèlach, P. Mutjé, Approaching a lowcost production of cellulose nanofibers for papermaking applications, Biores. 2015, 10, 5345-5355. https: //doi.org/10.15376/biores.10.3.5345-5355

51. G. Latta, A.J. Plantiga, M.R. Sloggy, The effects of Internet use on global demand for paper products, J. For. 2016, 114, 433-440. https://doi.org/10.5849/jof.15-096

52. R. Blell, Exilva cellulose fibrils to reduce environmental footprint and improve performance, $2^{\text {nd }}$ Annual Cleaning Product Sustainability Conference in Milan, February 5, 2019.

53. M.S. Reid, M. Villalobos, E.D. Cranston, Benchmarking cellulose nanocrystals: from the laboratory to industrial production, Langmuir 2017, 33, 1583-1598. https://doi.org/10.1021/acs.langmuir.6b03765

54. S.C. Patankar, S. Renneckar, Greener synthesis of nanofibrillated cellulose using magnetically separable TEMPO nanocatalyst, Green Chem. 2017, 19, 4792-4797. https://doi.org/10.1039/c7gc02383a 
55. For a recent application of SiliaCat TEMPO and Karimi's catalyst TurboBeads TEMPO to the in high yield electrocatalytc oxidation of 5-hydroxymethylfurfural to 2,5-diformylfuran, see: P. Kisszekelyi, R. Hardian,H. Vovusha, B. Chen, X. Zeng, U. Schwingenschlogl, J. Kupai, G. Szekely, Selective electrocatalytic oxidation of biomass-derived 5-hydroxymethylfurfural to 2,5-diformylfuran: from mechanistic investigations to catalyst recovery, ChemSusChem 2020, 13, 3127-3136. https://doi.org/10.1002/cssc. 202000453

56. F. Meneguzzo, C. Brunetti, A. Fidalgo, R. Ciriminna, R. Delisi, L. Albanese, F. Zabini, A. Gori, L.B. dos Santos Nascimento, A. De Carlo, F. Ferrini, L.M. Ilharco, M. Pagliaro, Real-scale integral valorization of waste orange peel via hydrodynamic cavitation, Processes 2019, 7, 581. https://doi.org/10.3390/ $\operatorname{pr} 7090581$

57. Dr. Cristiane Sanchez Farinas, personal correspondence with M.P., June 2021.

58. J. Pere, T. Tammelin, P. Niemi, M. Lille, T. Virtanen, P. A. Penttila, P. Ahvenainen, S. Gronqvist, Production of high solid nanocellulose by enzyme-aided fibrillation coupled with mild mechanical treatment, ACS Sustainable Chem. Eng. 2020, 8, 51, 18853-18863. https://doi.org/10.1021/acssuschemeng.0c05202

59. J.A. Shatkin, T.H. Wegne, E.M. Bilek, J. Cowie, Market projections of cellulose nanomaterial-enabled products-Part 1: Applications, Tappi. J. 2014, 13, 9-16.

60. K. Nelson, D. Turpin Advancing Commercialization of Nanocellulose: Critical Challenges Workshop Report, Advancing Commercialization of Nanocellulose: Critical Challenges Workshop, Washington, DC, May 7-8, 2019. https://doi.org/10.13140/rg.2.2.33789.59363

61. S. Dastager, Highly yield production of bacterial nano-cellulose useful for making medical and personal care products, Match Maker/ Renewable Chemicals \& Materials, TechEx.in, 16 Apr 2021.

62. Products using nanocellulose in Japan, Nanocellulose.com, 2021. https://nanocellulose.biz/en/products/ (accessed May 9, 2022).

63. B. McClay cit. In: N. Meyersohn, Rising wood prices are making your toilet paper more expensive, CNN Business, May 7, 2021. https://edition.cnn.com/2021/05/07/business/wood-pulp-prices-toiletpaper/index.html (accessed May 9, 2022).

64. R. Ciriminna, N. Chavarria-Hernandez, A. Rodriguez Hernandez, M. Pagliaro, Pectin: a new perspective from the biorefinery standpoint, Biofuel. Biopr. Bioref. 2015, 9, 368-377. https://doi.org/10.1002/bbb. 1551

65. E. Tsouko, S. Maina, D. Ladakis, I. K. Kookos, A. Koutinas, Integrated biorefinery development for the extraction of value-added components and bacterial cellulose production from orange peel waste streams, Ren. Energy 2020, 160, 944-954. https://doi.org/10.1016/j.renene.2020.05.108

66. P.G. Jessop, L.M. Reyes, GreenCentre Canada: an experimental model forgreen chemistry commercialization, Phys. Sci. Rev. 2018, 3, 20170189. https://doi.org/10.1515/psr-2017-0189

67. R. Ciriminna, L. Albanese, F. Meneguzzo, M. Pagliaro, Educating the managers of the bioeconomy, Authorea 2021, https://doi.org/10.22541/au.164004623.37302520/v1 